\title{
A INFORMAÇÃO: DESAFIO ÉTICO NA ERA DA GLOBALIZAÇÃO CONTEMPORÂNEA ${ }^{1}$
}

\author{
Sara Sofia Lúcio Vargas ${ }^{2}$ \\ (Centro de Filosofia da Universidade de Lisboa)
}

\begin{abstract}
A globalização constitui um processo de transformações que aparentemente aproxima os "quatro cantos" do mundo. Na era da globalização o mundo e o que nele acontece é apresentado como um todo, em que as suas partes são constituintes desse todo e apenas nele, com ele relacionadas, podem fazer sentido. Esta é a aparência do fenómeno da globalização.

Contudo, atente-se que tal, nos moldes em que a vivemos, surge com a necessidade crescente de expansão dos "mercados", de procurar as fontes que os saciem. Há, pois, um substrato económico neste fenómeno que se incrusta cada vez mais na nossa contemporaneidade. Mas esta incrustação contemporânea tem uma particularidade que para ela concorre: o desenvolvimento dos meios tecnológicos e o consequente desenvolvimento dos meios de informação e comunicação ${ }^{3}$. Debruçar-nos-emos sobre isto: a informação na era da globalização e a sua ética.
\end{abstract}

1 Texto submetido e premiado no âmbito da $3 .^{\mathrm{a}}$ edição do concurso de ensaio realizado por iniciativa da Área Científica de Filosofia da Faculdade de Ciências Humanas da Universidade Católica Portuguesa.

2 svargas@campus.ul.pt

3 Para o efeito do presente texto, não serão considerados meios informais de comunicação, por exemplo, blogs, sitios pessoais na internet, etc.

Philosophica, 51, Lisboa, 2018, pp. 131-135. 
Quando se procura pensar uma questão tão importante como a globalização dificilmente não salta à vista a enorme transformação e difusão que os meios de informação atuais registam. Esta será, seguramente, uma das questões hodiernas mais relevantes para o rumo da civilização.

Os novos meios de informação, essencialmente computacionais, conseguem chegar a todo o lado desmente tenham as condições mínimas para o efeito. Por exemplo, televisão, computador, telemóvel, entre outros apetrechos, e, claro, o mais essencial - acesso à internet ${ }^{4}$.

Por conseguinte, se questiona, pois, se essa maior difusão da informação se traduz numa democratização da mesma, seja na sua conceção, seja no acesso à mesma. Quais as consequências de uma tão elevada omnipresença da informação? Pode tal omnipresença transformar-se rapidamente em omnipotência ou já o é? A omnipotência, de uma forma de estar da humanidade eventualmente "comercializada" pelos seus meios modernos de comunicação, poderá mitigar conflitos ou, ao invés, exacerba-os?

Estas questões, porventura, levantarão um sentido ético para a reflexão em torno da globalização e dos desafios que atualmente se podem colocar ${ }^{5}$. Assim se parece colocar a importância de pensar o lugar da informação nesta era da globalização.

É possível que a uma massificação da informação - e aqui poderá interessar ter em consideração o tipo de conteúdos mais veiculados, bem como o reduzido número de agências de informação internacional que, por sua vez, procedem à distribuição mundial da informação - não esteja a

4 É por causa da rede global e da tecnologia que lhe está associada que Castells não aceita como terminologia para a sociedade atual: "sociedade da informação" ou "sociedade do conhecimento", pois tanto a informação como o conhecimento sempre foram essenciais. O que agora distinguirá a nossa sociedade hodierna serão "as redes", cf. Manuel Castells, "A Sociedade em Rede: do Conhecimento à Política". In: Manuel Castells; Gustavo Cardoso (org.), A Sociedade em Rede: Do Conhecimento à Acção Política. Lisboa: Imprensa Nacional - Casa da Moeda, 2006, pp. 17-18. Do mesmo autor também se pode consultar com propósito: La Galaxia Internet. Barcelona: Areté, 2001. Num sentido semelhante, Ilharco refere uma "viragem computacional", no entanto, procurava destacar aquilo que hoje se entende como "filosofia da informação", o que não é impeditivo, bem pelo contrário, de se refletir a sua relação com a globalização e a ética, cf. Fernando Ilharco, "Filosofia da Informação: Alguns problemas fundadores". II Congresso Ibérico de Ciências da Comunicação-www.cccc2004.ubi.pt, p. 6 e pp. 15-16.

5 Poderá ser interessante a leitura de Luciano Floridi, The Ethics of Information. Oxford University Press, 2013; ou ainda, do mesmo autor, pioneiro da "filosofia da informação", e à responsabilidade da sua edição: The Cambridge Hand book of Information and Computer Ethics. Cambridge: Cambridge University Press, 2010. 
corresponder igual progresso democrático ${ }^{6}$.

Não será por acaso que se diz que os meios de comunicação social são o "quarto poder" (sê-lo-á assim desde as primeiras Revoluções liberais). Mas, se os outros poderes convencionais - legislativo, executivo e judicial - são, em quase todo o mundo, eleitos democraticamente (ou nomeados por vias democraticamente eleitas), com os Media já não será, propriamente, a mesma coisa. Ou estes pertencem ao Estado (o que poderia lograr, de certa maneira, uma ligação indireta ao poder democraticamente eleito, o que nem sempre garante a sua idoneidade) ou pertencem, em geral, a grandes grupos privados, que muitas das vezes não tratam apenas de comunicação, mas também possuem investimentos financeiros noutras áreas.

Os Media têm conseguido ao longo dos anos influenciar quedas e ascensões de governos, de políticos (entre outras personalidades); os Media têm até justificado invasões de umas nações por outras, bem como, propalado ódio (mesmo que não seja seu desiderato); etc.

Talvez se possa pensar que uma tão grande influência não seja necessariamente perniciosa, pois os povos decidem com base na informação que se procura, prima facie, o mais ampla possível. Contudo, será que a informação veiculada tem realmente procurado mostrar todos os ângulos da questão que aborda? Será que não é, por exemplo, permeável aos anseios de mercado (e/ou políticos de outro tipo)? Quer dizer, será que, aqueles a quem incumbe passar a informação (mais propriamente os que a redigem), não acabam por ter, em primeiro lugar, de garantir as audiências, os leitores, e os seus postos de trabalho por consequência e, apenas em segundo lugar, informar devidamente? Em suma, é possível traçar-se uma fronteira inequívoca entre informação e propaganda (política ou publicitária)?

Parece que se encontra aqui o paradoxo fundamental da informação nesta era da globalização: quanto mais massificada, menos democrática parece tornar-se e mais propagandística.

Portanto, o que importa será refletir no tipo de omnipresença que os meios de comunicação atuais conquistaram 7 . Quando se fala na capacidade que o desenvolvimento da globalização tem para aproximar os "quatro cantos" do mundo, sacudir preconceitos e até homogeneizar, à guisa

6 Para isto terá contribuído a Conferência do G7 de 1995 onde, no que se refere à expansão da informação, tais nações a terão confiado ao mercado e ao "princípio de competitividade" descurando a "diversidade cultural como muito polémica", cf. Armand Mattelart, A globalização da comunicação. Tradução de Laureano Pelegrin. Bauru, SP: EDUSC, 2000, p. 181 (La mondialisation de la communication, 1996).

7 Por exemplo, Floridi equipara o processo de uma "infoesfera global" ao de um "ecossistema", cf. Floridi, op. cit., pp. 8-9. 
pretensamente cosmopolita, a postura dos mais diversos povos, não se pode eximir à responsabilidade que os Media têm tido nesse mesmo processo. Porventura, não estará, tal presença, a contribuir para a criação de um falso consenso acerca de uma forma de estar da humanidade?

Tratando-se realmente de um falso consenso, isto é, criado artificialmente com propósitos não (ou pouco) divulgados, tal se poderá encontrar, poderíamos dizer, empiricamente comprovado pela situação de conflitualidade internacional. A tensão que se regista entre as diversas nações, seja do ponto de vista cultural, religioso, económico, etc., não logra qualquer superação por via de uma informação uniformizada, antes pelo contrário, parece que se levanta maior hostilidade.

Este parece ser um dos perigos da informação tal como se tem revelado globalmente. $\mathrm{O}$ chamado mainstream parece ter, cada vez mais, adquirido "força de lei". À informação parece, por vezes, caber confirmar os preconceitos de uma generalidade da população ou formar os próximos preconceitos geralmente aceites. À informação também parece estar associada uma omnipotência facilitada pela concentração dos "donos da informação".

Não obstante, todo o poder dos Media, estes acabarão sempre por dar ou fortificar o poder político, económico e/ou militar, sendo este(s) a exercer efetivamente o poder que do primeiro veio um "empurrão".

Enfim, os Media terão duas facetas. Por um lado, uma de que neste espaço procurámos dar conta - o seu lado negativo, por assim dizer, potencialmente propagandístico, dissimulado e pouco democrático -; e, por outro, o seu lado positivo - o de veiculador e guardião da informação, para que esta possa ser divulgada e não ocultada e/ou deturpada.

Mas é por haver, e se registar aqui e ali, com bastante incidência, o primeiro caso, que é importante pensar-se a informação e os meios através dos quais esta é divulgada nesta era de globalização, onde a maior parte da população mundial pode cair num mesmo logro.

Essa manipulação da informação falta muitas vezes à correspondência com a realidade que se quer mostrar, servindo propósitos contrários aos da própria informação. Alguém "informado" hoje pode não ser necessariamente alguém que possua dados suficientes para se considerar conhecedor de um determinado assunto. Falta-se à ética de seguir autonomamente o propósito de informar.

Registamos, pois, a importância de um sentido ético no âmbito da informação global. Sem um tal esforço, é possível que se fique cada vez mais à mercê das mais variegadas manipulações. Aqui, terminaríamos evocando uma passagem de Guattari: «[o que é preciso é] criar novos universos de 
referência a fim de abrir caminhos à reapropriação e a uma ressimbolização do emprego dos instrumentos de comunicação e informação fora das fórmulas repisadas do marketing» ${ }^{8}$. Não será possível qualquer informação sem sociedade, então, cabe perceber que tipo de sociedade se pretende construir global, informacional e eticamente.

${ }_{8}$ Félix Guattari (Chaosmose, 1992), apud Mattelart, op. cit., p. 180. 